\title{
Hospital morbidity pattern in children under 1 year of age born in Sheffield 1975-6
}

\author{
BARBARA LLOYD, EDNA PURSALL, AND JOHN L EMERY \\ Department of Pathology, Children's Hospital, Sheffield
}

SUMMARY The morbidity pattern, based on hospital admissions for a complete year's cohort of all children born in Sheffield 1975-6, was studied. In many children the diagnosis given on admission had changed by the time they were discharged from hospital. About one-quarter of children under age 6 months were admitted for social reasons. Despite a decreasing birth rate the admission rate had increased, with an overall admission rate of $11.2 \%$ of all births. The rates and ages at which children are admitted varied greatly according to the month of birth. This is an important factor if cohort studies from different places are being compared.

While a large amount of information is available on ages and the diseases of children admitted to hospitals, there is little on what happens to complete communities of children. Our attention became focused on the hospital admission aspect of infant morbidity when we found that the discriminate function that identified infants liable to unexpected death also served to identify children requiring admission to hospital. ${ }^{1}$ Since 1975 we have extended our epidemiological mortality interests to infant morbidity and we now survey the state of each baby at age 1 month. We thus have continuing information for every Sheffield infant at the time of birth and at 1 month; this has enabled us to monitor, as far as hospital admission is concerned, the morbidity rate of all children born in the city.

Before attempting to produce methods of identifying children at increased risk of particular diseases, it became necessary to relate the admission diagnosis to the final diagnosis, irrespective of the number of times each child was admitted. For this reason, a year's cohort of babies was taken and all hospital notes scrutinised from the point of view of initial and final diagnosis. This was done irrespective of the hospital or place in which the child was admitted, and the number of readmissions.

\section{Materials and methods}

The cohort comprised 5600 children born between 1 August 1975 and 31 July 1976 to families living within the Sheffield Area Health Authority; 5546 $(99.6 \%)$ were born in maternity hospitals and 54 at home.
The admission of all children to all hospitals in the area is abstracted daily and this information was added to each child's record sheet. We thus have a record of every hospital admission and of every child born and living within the Sheffield area. Following this, with the consent of the clinical consultants, the case notes of every admission of each Sheffield child admitted were scrutinised by a paediatric registrar and all admission and discharge diagnoses confirmed. The admission diagnosis was the diagnosis on the ward's admissions register and the final diagnosis that given to the family doctor on discharge.

The diagnoses were then grouped in a simplified form as shown in the Table. All admissions were noted until each child was a year old-that is, those born on 1 August 1975 were followed until 31 July 1976.

We could not record babies transferred within the maternity hospitals to the same hospital's special care units. In Sheffield, the neonatal surgical unit is sited some distance from the maternity hospitals and so all neonatal surgical transfers were recorded as hospital admissions.

Sheffield has a very stable population and our study of babies during the first 5 weeks after birth indicates that there is a transfer in and out of the city of between 8 and 10 babies a month, making a total of no more than 120 in a year.

\section{Results}

In all, $605(11 \%)$ of all children required hospital admission, several requiring multiple admissions, 
Table Breakdown of the year's cohort admissions

\begin{tabular}{|c|c|c|c|c|c|c|}
\hline & \multirow[t]{2}{*}{ No of admissions } & \multirow{2}{*}{$\begin{array}{l}\text { No of children } \\
\text { admitted }\end{array}$} & \multirow[t]{2}{*}{ Single admissions } & \multicolumn{2}{|c|}{ Admissions } & \multirow{2}{*}{$\begin{array}{l}\% \text { repeat } \\
\text { admission }\end{array}$} \\
\hline & & & & $\times 2$ & $\times 3$ & \\
\hline \multicolumn{7}{|l|}{ Infections } \\
\hline Respiratory tract & 204 & 180 & 129 & 13 & & 12 \\
\hline Gastrointestinal & 129 & 120 & 83 & 5 & 1 & 7 \\
\hline Others & 47 & 44 & 30 & 2 & & 6 \\
\hline \multicolumn{7}{|l|}{ Malformations } \\
\hline Central nervous system & 38 & 16 & 6 & 4 & 6 & 58 \\
\hline Cardiovascular system & 23 & 9 & 3 & 2 & 2 & 61 \\
\hline Others & 14 & 13 & 11 & 1 & & 7 \\
\hline Medical & 81 & 65 & 46 & 5 & 3 & 20 \\
\hline Surgical & 74 & 70 & 54 & & 1 & 5 \\
\hline Trauma & 55 & 53 & 37 & 2 & & 3 \\
\hline Social problems & 51 & 35 & 12 & 3 & 3 & 31 \\
\hline Feeding problems & 104 & 89 & 58 & 6 & 1 & 14 \\
\hline Total & 820 & & 469 & 43 & 17 & \\
\hline
\end{tabular}

there being a total of 820 admissions. These admissions comprised $8 \%$ of all children born who were admitted once, $7 \%$ who were admitted twice, and $3 \%$ who were admitted three times.

The ages of the children on admission are shown in Fig. 1 . There was an early peak in the period between 5 and 8 weeks, a lower level between 29 and 36 weeks, and a second rise in the 48 -week period. The general headings under which the infants were admitted and the classification on final diagnosis, together with the number of readmissions, are shown in the Table; the data for the whole year are given too.

The pattern of admission varies according to the age of the children (Fig. 2). There was a progressive

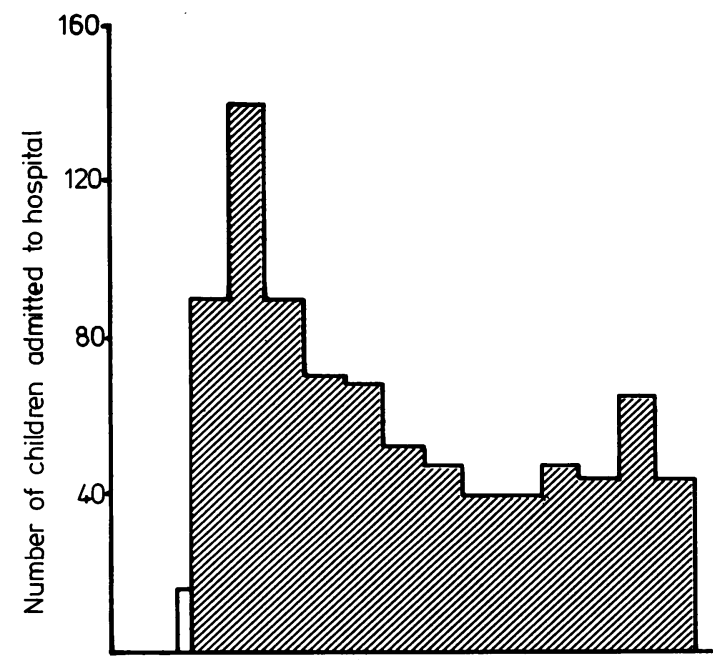

$\begin{array}{llllllllllllll}1 & 2 & 3 & 4 & 5 & 6 & 7 & 8 & 9 & 10 & 11 & 12 & 13\end{array}$ Age (months) at time of admission

Fig. 1 Age at admission. Small white block (left) represents the neonatal surgical transfers from the obstetric units. fall in babies admitted with feeding problems, from $22 \%$ in the age group $0-3$ months to $5 \%$ at the end of the year. Cases of infection only varied between $\mathbf{4 0}$
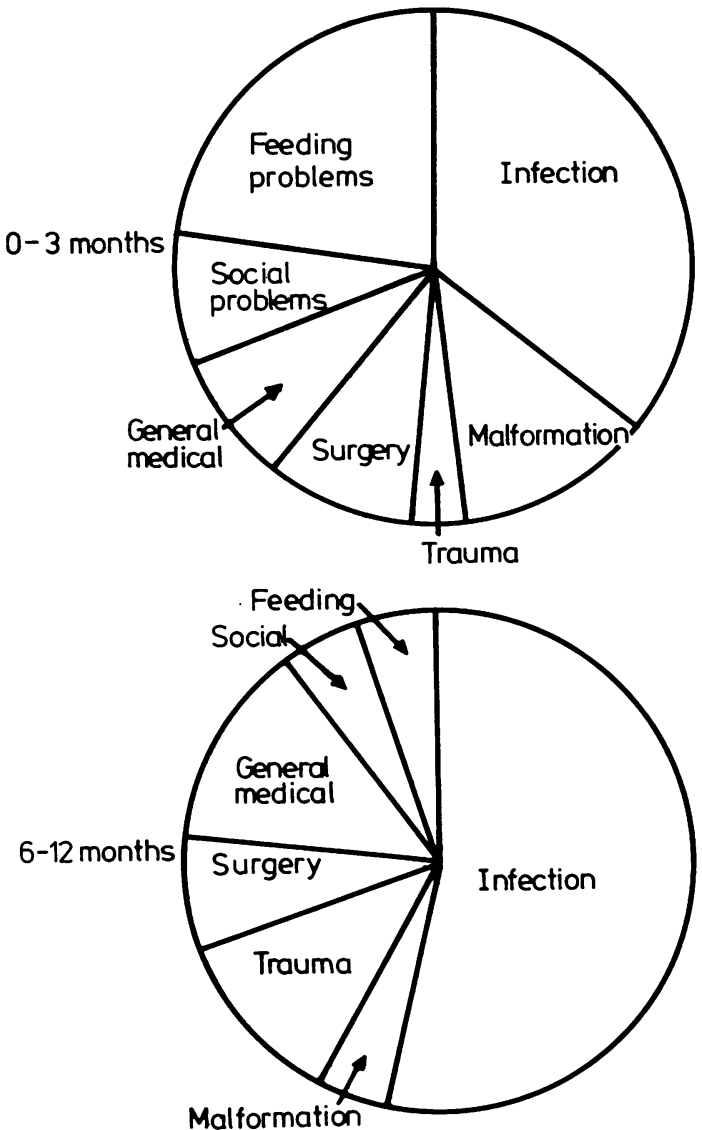

Fig. 2 Chart showing how admission patterns differ according to the age of the infants during the first year. 
and $55 \%$ during the year, but admission for trauma showed a steady rise.

$13 \%$ of children were discharged with a diagnosis that was different from that at admission. 13 of 19 children admitted for surgery were discharged with a diagnosis of feeding problems, and 10 of 98 babies admitted for feeding problems required surgery. The largest group to change the diagnosis was that related to social problems, and $46 \%$ of children discharged with the diagnosis of social problems had been admitted with other diagnoses.

The diagnosis of social problems showed an interesting pattern. The change in diagnosis always moved in the direction of social problems, suggesting that many admission diagnoses are 'excuses for admission'. There were 33 direct admissions as social problems, and 18 more children were recognised in the wards.

The admission rate of babies related to age is shown in Fig. 1, but when broken down into cohorts of babies born in different months of the year a varying pattern emerged for each group. The overall admission rate for the year for babies born between December and February was $14.3 \%$, between March and May $13.3 \%$, between June and August $13.2 \%$, and between September and November $14 \cdot 3 \%$. But when the age at which each baby was admitted was graphed, a different pattern emerged. The ages at admission of the January (446), April (460), and August (487) cohorts are shown in Fig. 3.

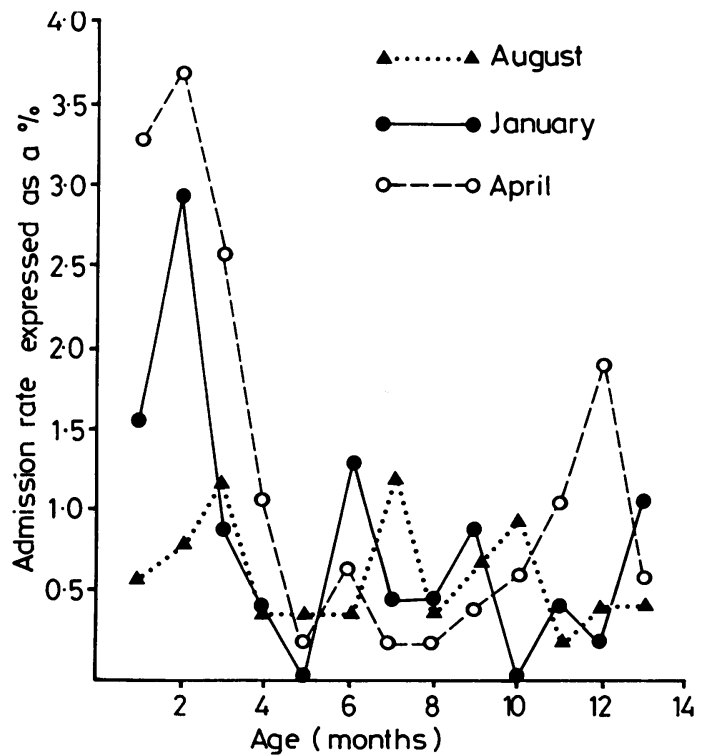

Fig. 3 'Age at admission' pattern of children born in January, April, and August.

\section{Discussion}

Although the number and type of child deaths can be a reflection of the pattern of severe disease in a community, the pattern of disease for which children are admitted to hospital is perhaps a less clear reflection of the morbidity of children in the community, ${ }^{2}$ as it reflects too the referral and admission policy of the local doctors. The information that we report here is thus as much a reflection on contemporaneous community paediatric care as on morbidity. This is particularly relevant in Sheffield where there is no overall shortage of hospital beds for children and there is a hospital policy never to refuse a request for admission.

The admission pattern of our baby cohort needs to be seen first against the general admission rate for Sheffield-born babies during different months of the year (Fig. 4). Despite a falling birth rate, there has been, if anything, a rise in admission rate during the last 3 years. The most striking feature is the wellknown summer to winter variation in admission rates; during peak times, there are about double the number of admissions of the late summer months. The peak winter admission rate in the city occurs in different months in different years.

Perhaps the most important result was the age pattern of admissions with children born during different months of the year, the most striking being the difference between the August 1975 cohort, and that of July 1976 which had a remarkably high admission rate during the first few months. These results may partly be the effect of using cohorts of only about 500 babies but they show the possible dangers of drawing conclusions from a single month's cohort of babies, as used in the Newcastle 1000 baby study $^{3}$ and in the British Perinatal Mortality Survey ${ }^{4}$ where only particular months' birth cohorts were followed. It will obviously be necessary for us to follow and compare monthly cohorts over several years, but a scan of the local figures suggests that

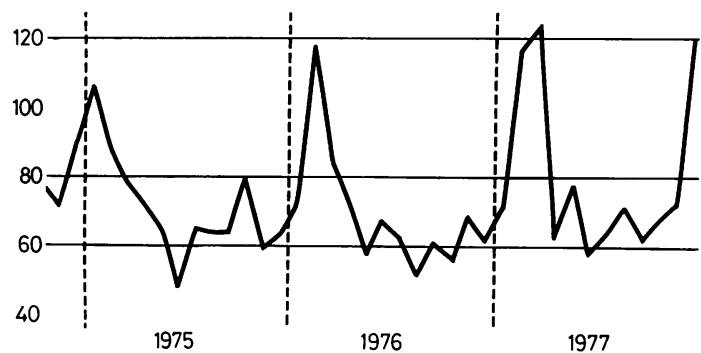

Fig. 4 Monthly hospital admission rates for Sheffield-born children over a 3-year period. 
other years follow a similar pattern. The age of admission must also be seen against the admission rates for different month's cohorts. Thus the January 1975 cohort (446 infants) had an admission rate of $10.3 \%$ infants, the April (460 infants) a rate of $16.5 \%$, and the August (487 infants) a rate of $8.7 \%$ - that is only a little over half of the April babies.

In view of this variability, it seems of little value to compare our findings in detail with other surveys. Thus, our own admission rate of $11.2 \%$ for a year's 5600 infants over the whole year is greater than the Newcastle 1000 child August cohort rate of $10 \cdot 3 \%$, whereas our 487 August 1975 cohort had a rate of $8.7 \%$. As the month with the highest admission rate seems to change each year, local environmental factors could well shift a particular month's babies' morbidity pattern a month earlier or later. It is obvious that any future longitudinal studies of birth cohorts will need to define a policy of selection of the infants on a wider base than in the past.

Changes of diagnosis in hospital are of interest in relation to the diagnosis of social problems and transfers between medical and surgical care.

The age at which a child is most likely to be admitted as a social problem is in the 3- to 6-month period but, in all instances when a diagnosis involving social problems was made, the diagnosis always changed from some other diagnosis-such as, respiratory tract infection or feeding problems - to social problems, never the reverse. The term 'social problem' is an extremely loose one. If, as many suspect, most feeding problems have their basis in social factors, about one-quarter of all admissions under 6 months have this as a basis for admission. If so, a large section of hospital space is expensively equipped for an unnecessary variety of investigatory procedures. Thus, our comments will be similar to those of Wynne and Hull. ${ }^{5}$ For social problems, much simpler and more homely rooms, where there are ample facilities for parents, would be better, and probably could best be supplied on a day care basis.

The question of medical/surgical transfers is quite different, for here one is often dealing with very acute illness. 19 of 64 children requiring surgery were admitted as medical cases and 11 children admitted with suspected acute abdominal conditions were feeding problems. In our 'death conferences', it has become almost a truism that, if a patient dies on a surgical ward, he does so from a medical condition and vice versa! The concept of 'medicine' and 'surgery' in young babies must be kept extremely fluid and the benefits to the child of this type of separation must be balanced with the needs of professional convenience.

The present study only hints at the total morbidity in the infant population and we could well be looking at infant disease seen from the hospital through a very distorted lens. As we have stressed elsewhere, more acute infant deaths occur outside than inside the hospital. ${ }^{6}$ In a separate study that we have carried out on symptoms related to unexpected deaths and controls, it seems that, in Sheffield, on any one day, $2 \%$ of all infants under age 6 months who do not die will have 2 medical symptoms-for example, vomiting and diarrhoea, or cough and sleepiness-and less than half the infants are seen by a doctor. Our data indicate that, on average, there are 1.9 medical admissions in this age group a daythat is, about 1 in 12 of babies with symptoms is taken to see a doctor.

This study has exposed our ignorance of the morbidity rate of our children and emphasises the need for widely-based ongoing studies of infant and child morbidity outside the hospital.

\section{References}

1 Carpenter $R$ G, Emery $J$ L. The identification and follow-up of high-risk infants. In: Robinson $R$ F, ed. SIDS 1974. Francis E Camps International Symposium on Sudden and Unexpected Deaths in Infancy. Toronto: Canadian Foundation for the Study of Infant Deaths, 1975: 91-6.

2 Snook $\mathrm{H}$. The use of Glasgow hospital beds by children under the age of one year. Child Care Health Dev 1977; 3: 165-73.

3 Spence J, Walton W S, Miller F J W, Court S D M. $A$ thousand families in Newcastle-upon-Tyne. London: Oxford University Press, 1954.

4 Butler N R, Alberman E D. Perinatal problems. The Second Report of the 1958 British Perinatal Mortality Survey. Edinburgh: Livingstone, 1969.

5 Wynne J, Hull D. Why are children admitted to hospital? Br Med J 1977; ii: 1140-2.

6 Emery J L. In: Hull D, ed. Unexpected death in infancy. Recent Advances in Paediatrics 5. London: Churchill, 1976: 203-20.

Correspondence to Professor J L Emery, Department of Histopathology, The Children's Hospital, Western Bank, Sheffield S10 2TH.

Received 23 October 1979 